\title{
Incorporating Additional Sounding Observations in Weather Analysis and Rainfall Prediction During the Intensive Observing Period of 2006 TWP-ICE
}

\author{
Hsi-Chyi Yeh",* and Xiouhua Fu ${ }^{2}$ \\ ${ }^{1}$ Center for General Education, Aletheia University, Tamshui, Taiwan \\ ${ }^{2}$ International Pacific Research Center (IPRC), SOEST, University of Hawaii at Manoa, Honolulu, USA
}

Received 14 February 2011, accepted 11 April 2011

\begin{abstract}
Using additional sounding observations during the Intensive Observing Period (IOP) of the Tropical Warm Pool-International Cloud Experiment (TWP-ICE) in 2006, the characteristics of weather systems and associated environmental conditions are further analyzed during four temporal regimes (active wet monsoon, suppressed dry monsoon, clear day, and monsoon break). Monsoon low-pressure systems are predominant during the active wet monsoon and monsoon break periods. During the active monsoon period, heavy rainfall $\left(>100 \mathrm{~mm} \mathrm{day}^{-1}\right)$ is produced over the nearby tropical ocean of north Australia and the maritime continent centered on the Tiwi Islands, where the apparent southerly-to-southwesterly winds dominate at low levels over the ocean under the influence of the monsoon low in contrast to the westerly winds during a typical active north Australia summer monsoon regime. In the monsoon break, limited scattered rainfall is distributed over coastal regions of northern Australia and inland.

During the suppressed monsoon period and clear days, the environment is very dry under the influence of a monsoon ridge. This is not favorable for the development of convection and the production of the rainfall. In a suppressed monsoon regime, the dry air intrusion in the mid-troposphere with the driest center around the $600-\mathrm{hPa}$ level is related to dry air advection from the subtropical regions and the subsidence associated with the approaching of a monsoon ridge. Typical westerly winds prevail between 850 and $700 \mathrm{hPa}$ in Darwin. During clear days, the subsidence related to the monsoon ridge is the major reason for the driest environmental condition during 2006 TWP-ICE. With the help of additional sounding data, dominant weather systems during four periods are clearly identified when compared with NCEP/FNL global analysis. Also the daily rainfall predictions are improved during the IOP, especially in the active monsoon period.
\end{abstract}

Key words: TWP-ICE, Monsoon, Sounding

Citation: Yeh, H. C. and X. Fu, 2011: Incorporating additional sounding observations in weather analysis and rainfall prediction during the intensive observing period of 2006 TWP-ICE. Terr. Atmos. Ocean. Sci., 22, 421-434, doi: 10.3319/TAO.2011.04.11.01(A)

\section{INTRODUCTION}

The Tropical Warm Pool-International Cloud Experiment (TWP-ICE) collected an extensive dataset in northern Australia regions, during January and February 2006 (May et al. 2008). A comprehensive observation campaign around Darwin, using a ship and five aircraft as well as additional soundings advanced weather and climate studies resulting in an improved understanding and modeling of cloud processes in tropical cloud systems (May et al. 2008). A range of different observations collected during TWP-ICE has

\footnotetext{
* Corresponding author

E-mail:yehhc123@gmail.com
}

been used for the model evaluations (Wapler et al. 2010). In this study, the additional sounding observations, except the conventional sounding data collected at Darwin, are directly utilized in the weather analysis.

Based on the time series of radar-derived area-averaged daily rain-rate, Wapler et al. (2010) identified four distinct temporal regimes (active monsoon, suppressed monsoon, clear day, and monsoon break) during the intensive observing period (IOP). The active monsoon period with features of maritime convection and monsoon break period with characteristics of diurnally forced continental convection are also revealed. As analyzed by Xie et al. (2010), the midlevel subsidence and horizontal dry advection are 
largely responsible for the dry mid-troposphere observed during the suppressed period and limit the growth of clouds to low levels. Using sounding data from the IOP during the TWP-ICE period, Zhang (2009) indicates that the entrainment of the environment dry air has a strong dilution effect on the convective availability potential energy (CAPE). The undiluted CAPE varies in a range from 1000 to $5000 \mathrm{~J} \mathrm{~kg}^{-1}$, while the diluted CAPE is much smaller varying between 0 and $800 \mathrm{~J} \mathrm{~kg}^{-1}$. Because the moisture content is relatively higher during the active monsoon period, the diluted CAPE $\left(\sim 400-800 \mathrm{~J} \mathrm{~kg}^{-1}\right)$ is significantly larger than the other three temporal regimes. Under the suppressed monsoon and clear regimes, the diluted CAPE is much lower than that in the active monsoon due to dry air entrainment.

To further our understanding of the associated weather systems and conditions during the four temporal regimes of TWP-ICE intensive observing period, the additional rawinsonde observations over northern Australia from 21 January to10 February 2006 are used to incorporate the NCEP-FNL global analysis through data assimilation. This approach improves weather analysis and daily rainfall prediction over northern Australia and the nearby tropical ocean. Also, the characteristics of environmental conditions for the occurrence of rain-producing systems are investigated.

In this study, the data (sounding observations and TRMM rainfall) and the methodology [Advanced Research WRF (ARW) model and the associated three-dimensional variational (3D-Var) data assimilation system as well as statistical methods] are briefly introduced in section 2 . Weather analysis and rainfall prediction is discussed in sections 3 and 4. Major results are summarized in section 5.

\section{DATA AND METHODOLOGY}

\subsection{Data}

Four rawinsonde observations gathered from the RV Southern Surveyor, Garden Point, Cape Don, and Darwin covering northern Australia (Fig. 1) and the nearby Tiwi Island from 21 January to 10 February 2006 are utilized. The sounding data in the morning hours around 0000 UTC will be assimilated with a global analysis (NCEP/FNL) to generate a new dataset, which will serve as the model initial conditions for weather forecasting to reveal weather conditions during the four temporal regimes of TWP-ICE. In addition, satellite-retrieved $0.25^{\circ} \times 0.25^{\circ} \mathrm{TRMM}$ daily rainfall data are used to reveal rainfall distribution and also to evaluate the daily rainfall prediction.

\subsection{The Mesoscale Model and the Associated 3D-Var System}

To reveal the characteristics of weather conditions with additional sounding observations during four temporal regimes (active wet monsoon, a suppressed monsoon, clear days, and a monsoon break) of TWP-ICE, the Advanced Research WRF (ARW) mesoscale model (Skamarock et al. 2008) and WRF 3D-Var system which is developed from MM5 3D-Var (Barker et al. 2004) and used in many WRF data assimilations (e.g., Xiao and Sun 2007; Xiao et al. 2009; Yeh 2010) were utilized.

In the vertical, the ARW model has thirty-one sigma levels from the surface $(\sigma=1.0)$ to $50 \mathrm{hPa}(\sigma=0.0)$. A fine domain with $3-\mathrm{km}$ grid-spacing is nested within a coarse domain with 9-km grid spacing. The ARW model physics include planetary boundary layer (PBL) processes with the Yonsei University scheme (Skamarock et al. 2008), short-wave radiation (Dudhia 1989) and long-wave radiation (Mlawer et al. 1997), land surface physics (Chen and Dudhia 2001), and precipitation physics. The precipitation is calculated by both the explicit scheme with mixed-phase processes (Ferrier et al. 2002) and the parameterization of the Betts-Miller-Janjić scheme (Janjić 1994, 2000) for the coarse domain. For the nested domain, the precipitation is directly calculated by the explicit scheme using mixedphase processes (Ferrier et al. 2002).

To produce the optimal initial conditions for the numerical simulation, the WRF 3D-Var system is used to assimilate additional sounding data over the northern Australia regime. As will be shown in section 3, the assimilation of the sounding observations produces increments in the wind field and moisture content through the dynamical/physical constraints.

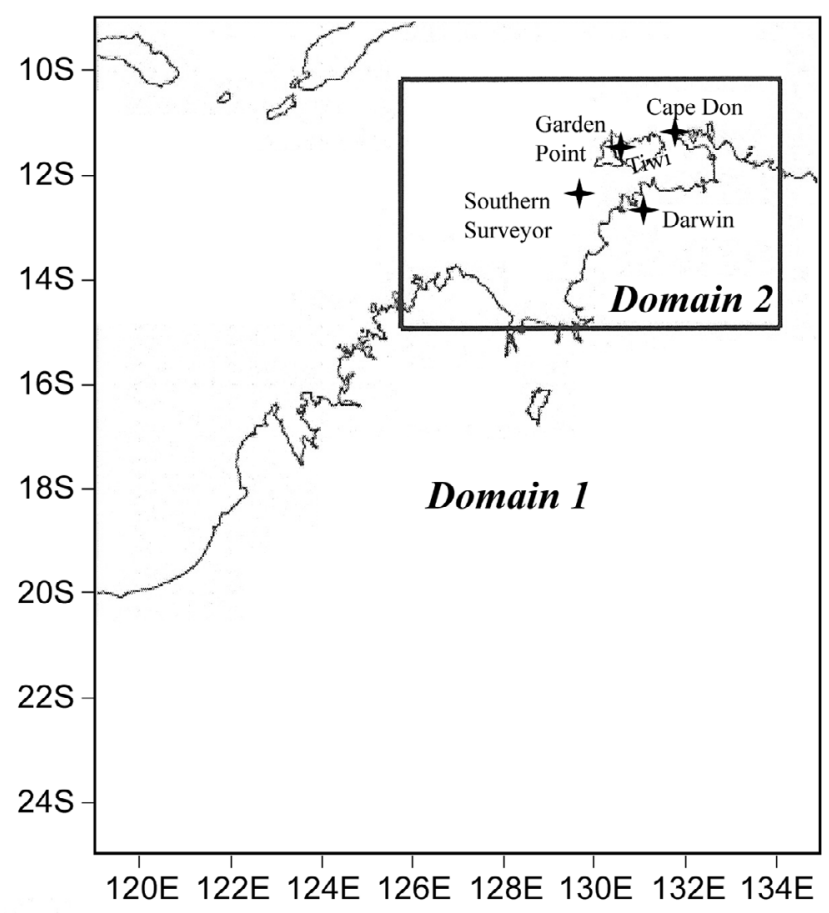

Fig. 1. Model domains with 9- and 3-km horizontal resolutions for the coarse domain and nested domain. Four sounding sites are presented at Cape Don, Garden Point, Darwin, and Southern Surveyor. 


\subsection{Statistical Methods}

Two statistical measures are utilized to quantify the improvement in the prediction of daily regional rainfall $\left(\geqq 20 \mathrm{~mm} \mathrm{day}^{-1}\right.$ ) over the open ocean west of Tiwi Island and northern Australia from 22 - 25 January 2006 within the active wet monsoon period. Note that the heavy rainfall event is only produced in this temporal regime and most of the rainfall is distributed over the open ocean (Fig. 2). Two predicted daily rainfall verification indices used here are the mean absolute error (MAE) and the bias (Wilks 1995), which are defined as

MAE $=\frac{\sum_{i=1}^{N}\left|F_{i}-O_{i}\right|}{N}$

bias $=\sum_{i=1}^{N} F_{i} / \sum_{i=1}^{N} O_{i}$

In Eqs. (1) and (2), $F_{i}$ and $O_{i}$ refer to forecast and observed
(TRMM rainfall) precipitation amount for point $i$ respectively, and the summation is over the number point $N$.

In Eq. (1), the MAE is the arithmetic average of the absolute values of the differences between the members of each pairs. Clearly the MAE is zero if the forecasts are perfect (i.e., $F_{i}=O_{i}$ ), and increases as the differences between the forecasts and observations become larger (Wilks 1995). For the bias calculation in Eq. (2), a value greater than 1 indicates an over-prediction. Conversely, a bias less than one indicates that the forecast under-predicted amounts when compared with the observations. A perfect bias is indicated by a value equal to 1 . Here, the MAE and bias for the regional daily rainfall predictions with and without additional sounding assimilation are presented in section 4 .

\section{WEATHER ANALYSIS}

During TWP-ICE field campaign period in 2006, the monsoon was across north Australia from 13 January to 2 February and then weakened in Australian/Indonesian
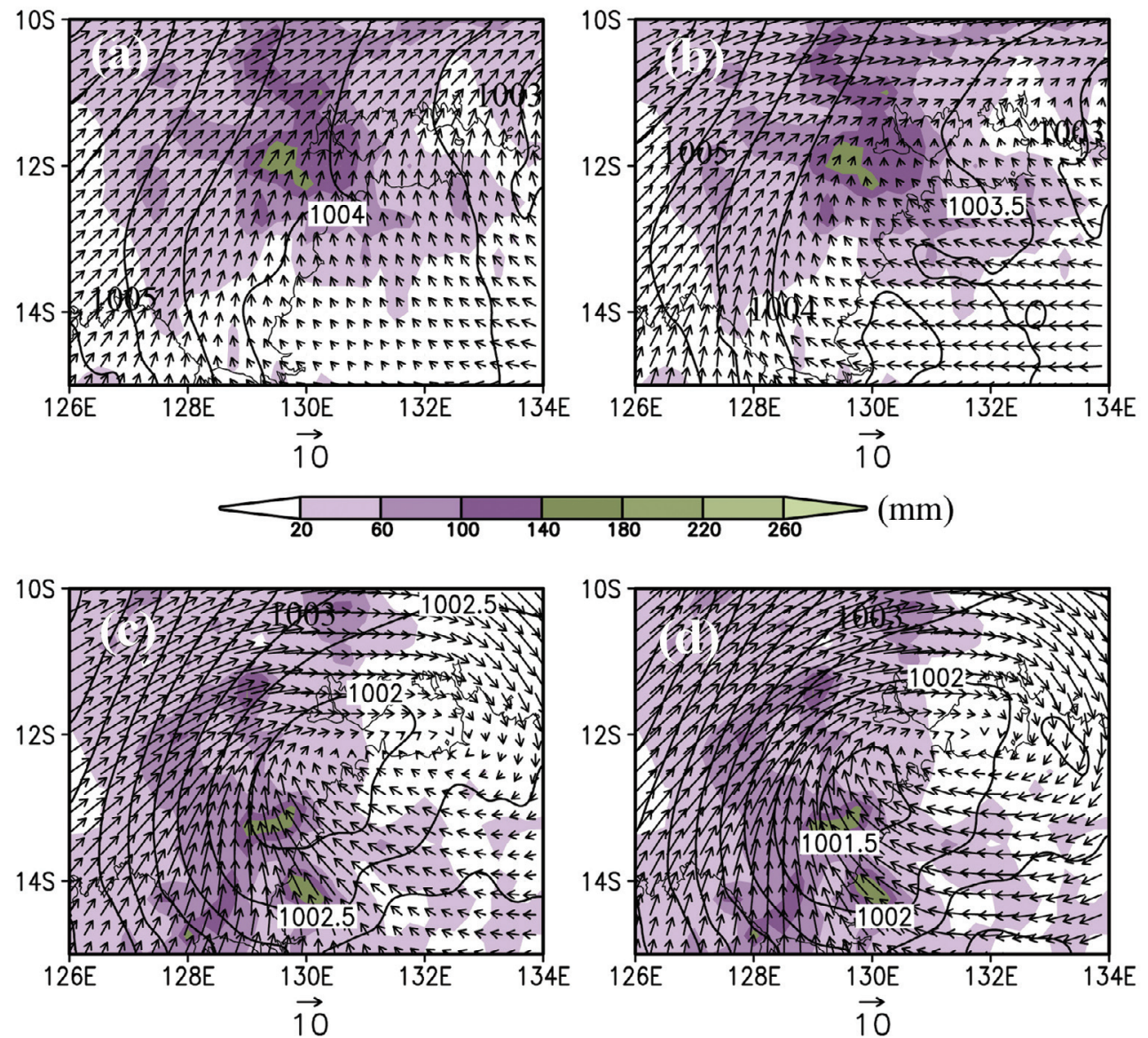

Fig. 2. (a) TRMM daily rainfall, NCEP/FNL sea-level pressure and 950-hPa wind vector (0000 UTC) on 23 January 2006, (b) TRMM daily rainfall, sea-level pressure and 950-hPa wind vector (0000 UTC) with assimilated sounding data on 23 January, (c) same as (a) but for 24 January, and (d) same as (b) but for 24 January. The rainfall (shading) with a $40 \mathrm{~mm}$ interval starts from $20 \mathrm{~mm}$. The contour of sea-level pressure has an interval of $0.5 \mathrm{hPa}$. 
regions from 3 - 13 February. Prior to 23 January, a monsoon low-pressure system and the tropical cyclone Daryl produced heavy rainfall $(>100 \mathrm{~mm})$ over the land in the north of Australia and in the coastal regions from $13-21$ January 2006 (Not shown). Because the additional raiwinsonde data was collected from 21 January, the analysis of weather conditions will focus on the following four temporal regimes (active wet monsoon, suppressed monsoon, clear day, and monsoon break) from 21 January to 10 February 2006 as revealed by previous studies (May et al. 2008; Wapler et al. 2010; Xie et al. 2010).

During the active wet monsoon period (21 - 25 January 2006), the sea-level pressure at 0000 UTC on 23 January reveals that a westward-moving monsoon low-pressure system is predominant over the north Australia land mass and surrounding tropical ocean based on the NCEP/FNL global analysis (Fig. 2a) and the data with the additional assimilated soundings (Fig. 2b). At the 950-hPa level, the southerly-to-southwesterly winds prevail over the tropical ocean (Figs. 2a and b). Heavy rainfall $(>100 \mathrm{~mm}$ ) is revealed by the TRMM daily rainfall over the nearby tropical ocean of north Australia and Tiwi Island. One day later, a deepening low-pressure center reaches the coastal regions with a significant anti-cyclonic circulation at the $950-\mathrm{hPa}$ level at 0000 UTC 24 January (Figs. 2c and d) and then moves southward along the coast. Meanwhile, the southerly wind component is enhanced in the south-to-southwest of the monsoon low (Figs. 2c and d), where heavy rainfall is revealed. In addition, the easterly wind increases over land. With the incorporation of additional sounding observations during TWP-ICE, the low-pressure system (Figs. 2b and d) is relatively stronger than that analyzed by the NCEP/FNL data (Figs. 2a and c). At the 850-hPa level, the mean wind and geo-potential height fields during active monsoon period also reveals that a monsoon low-pressure system with an anti-cyclonic circulation is located in the north of Australia (Fig. 3). The wind speed increases in the west and the south of the monsoon low pressure system, but decreases near the center of the monsoon low through the assimilation of additional soundings (Figs. 3b and c) compared with the global analysis (Fig. 3a). These indicate the dynamical adjustment through the assimilation of additional sounding data.

To further investigate the adjustment in the vertical atmospheric profiles during the active wet monsoon period through data assimilation, the vertical cross-section of mean wind speed and relative humidity along the Darwin is shown in Fig. 4. The atmospheric conditions have a relatively high humidity from low levels through upper levels within this period as compared with the following periods. With the sounding assimilation, the mean moisture field exhibits a small adjustment and becomes slightly wet below the 700hPa level (Fig. 4b) compared with the NCEP/FNL analysis
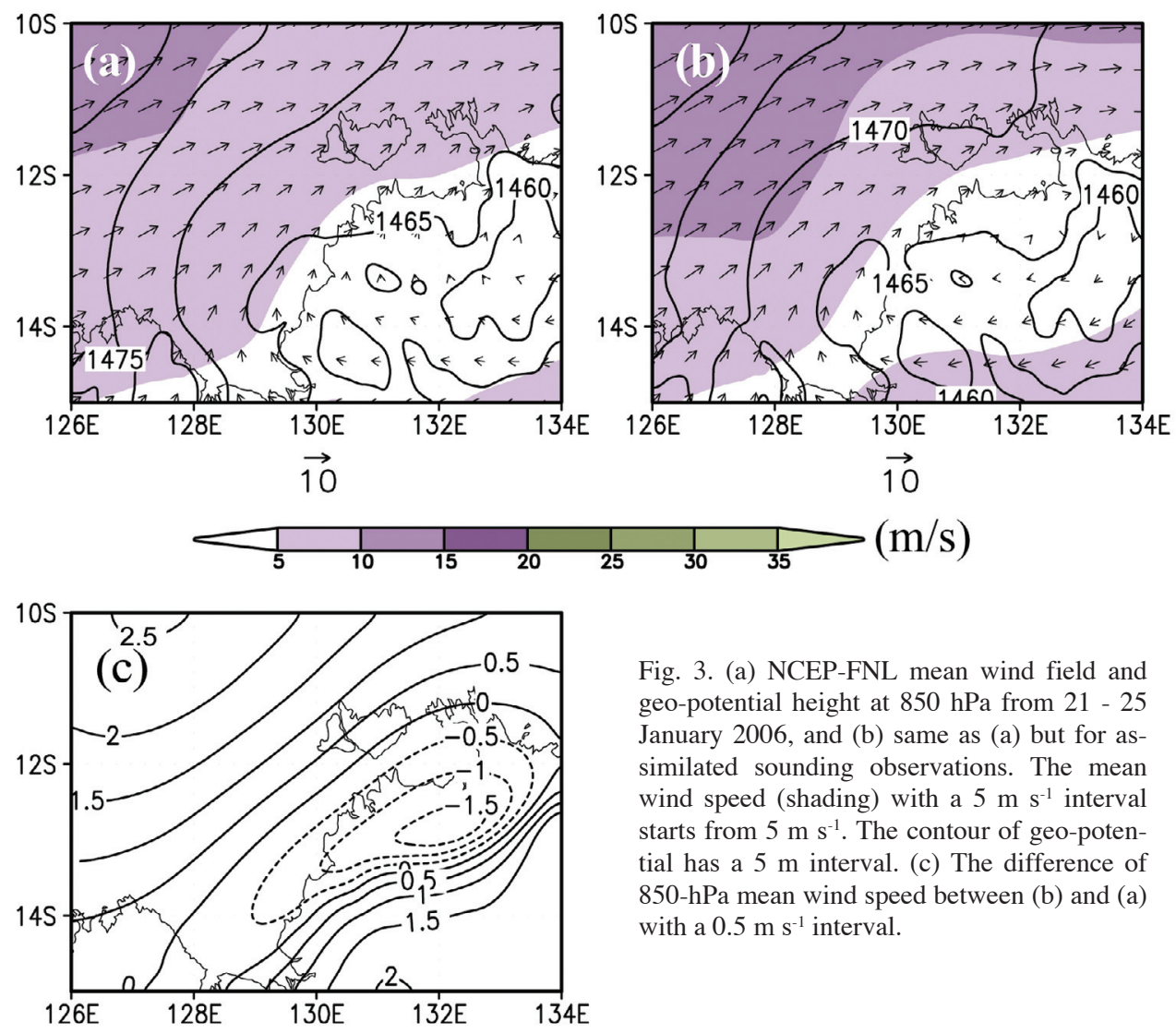

Fig. 3. (a) NCEP-FNL mean wind field and geo-potential height at $850 \mathrm{hPa}$ from $21-25$ January 2006, and (b) same as (a) but for assimilated sounding observations. The mean wind speed (shading) with a $5 \mathrm{~m} \mathrm{~s}^{-1}$ interval starts from $5 \mathrm{~m} \mathrm{~s}^{-1}$. The contour of geo-potential has a $5 \mathrm{~m}$ interval. (c) The difference of 850-hPa mean wind speed between (b) and (a) with a $0.5 \mathrm{~m} \mathrm{~s}^{-1}$ interval. 
(Fig. 4a). Through dynamical adjustment of the additional soundings, the mean wind speed below the 850-hPa level increases slightly in the west of the monsoon low, but decreases near the center. Meanwhile, the wind speed above the 350-hPa level increases with the assimilated sounding data. For the heavy rain episode at 0000 UTC on 24 January under the influence of a monsoon low pressure system, the low-level winds with assimilated sounding data (Fig. 5b) are enhanced compared with the NCEP-FNL analysis (Fig. 5a). The atmosphere is approximately saturated below $500-\mathrm{hPa}$ level (Fig. 5). The wind field with assimilated sounding data is characterized by strong northeasterly wind between the middle and the upper levels (Fig. 5b) east of Darwin. In contrast, low-level winds reveal strong southwesterly wind to the west of Darwin. On the basis of previous studies (Drosdowsky 1996; May et al. 2008), the principal feature of the north Australian monsoon in Darwin is the westerly winds between 850 and $700 \mathrm{hPa}$. However, the westerly wind during the active monsoon period of TWP-ICE field campaign is not significant.

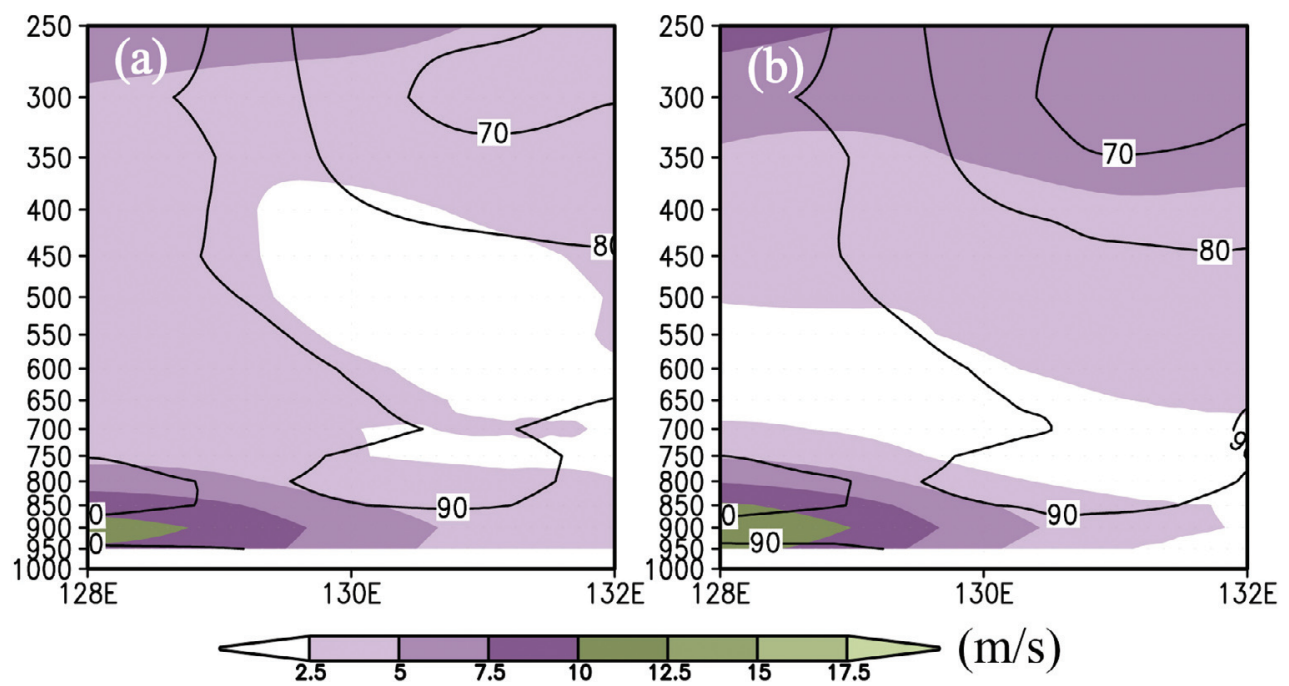

Fig. 4. (a) Vertical cross-section of NCEP/FNL mean wind speed and relative humidity along the Darwin (lat = -12.24) during $21-25$ January 2006 , and (b) same as (a) but for assimilated sounding observations. The mean wind speed (shading) with a $2.5 \mathrm{~m} \mathrm{~s}^{-1}$ interval starts from $2.5 \mathrm{~m} \mathrm{~s}^{-1}$. The contour of the relative humidity has a $10 \%$ interval.

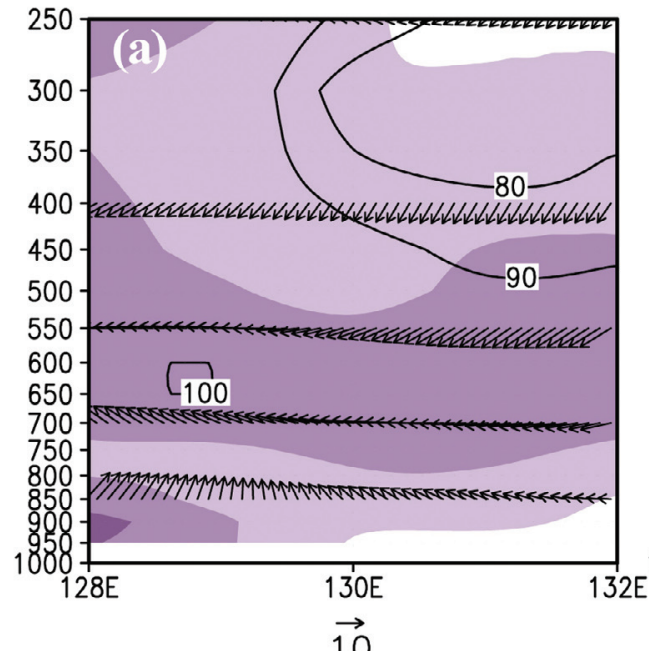

$\overrightarrow{10}$

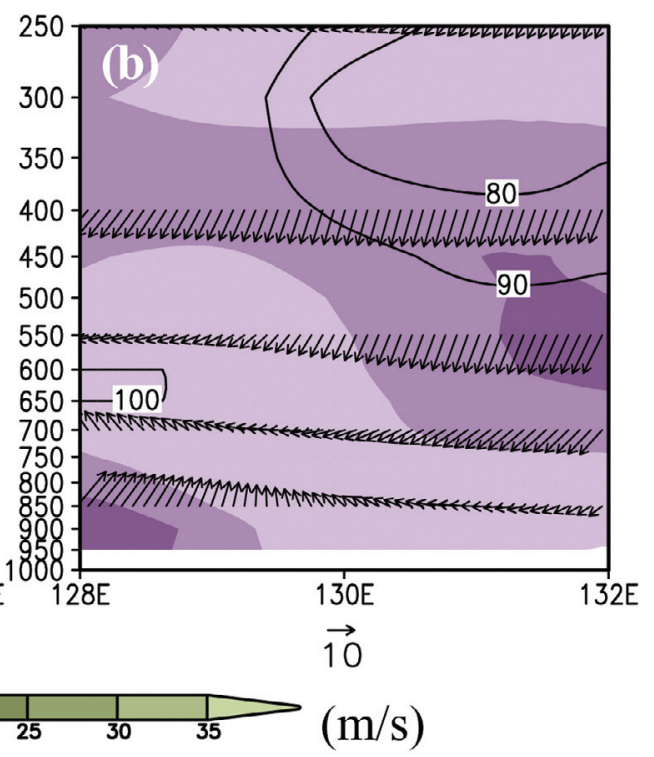

Fig. 5. (a) Vertical cross-section of NCEP/FNL wind field and relative humidity along the Darwin (lat $=-12.24$ ) at 0000 UTC on 24 January 2006 , and (b) same as (a) but for assimilated sounding observations. The mean wind speed (shading) with a $5 \mathrm{~m} \mathrm{~s}^{-1}$ interval starts from $5 \mathrm{~m} \mathrm{~s}^{-1}$. The contour of the relative humidity has a $10 \%$ interval. 
During the suppressed monsoon period (26 January 2 February 2006), the sea-level pressure gradient increases significantly (Fig. 6) and the winds change to strong westerlies over the tropical ocean and the northwesterlies over land compared with the active wet monsoon period. With the additional assimilated sounding observations, a monsoon ridge approaches Tiwi Island and the north Australian regions (Figs. 6b and d), while the northwesterlies are strengthened inland, as compared with the NCEP/FNL analysis (Figs. 6a and c) during 29 - 30 January. A much weaker TRMM rainfall (Fig. 6) indicates that this is in a really dry period compared with the active wet monsoon period. Using the sounding observations during TWP-ICE and the NCEP-FNL analysis, the mean wind fields at the 850-hPa level (Fig. 7) show that the westerly winds enhance apparently with the maxima greater than $20 \mathrm{~m} \mathrm{~s}^{-1}$ to the east of Darwin (Fig. 7b) under the influence of the approaching monsoon ridge. In addition, the westerly winds increase based upon the assimilated additional sounding observations (Figs. $7 \mathrm{~b}$ and c). The meridional gradient of the geo-potential height (Fig. 7) is much larger in the suppressed monsoon period than that in the active period (Fig. 3).
For the moisture content and the wind field adjustment in the vertical atmospheric profiles during the suppressed monsoon period, the mean vertical cross-section along the Darwin (Fig. 8) reveals that a significant dry center occurs at the $600-\mathrm{hPa}$ level. The mean moisture content within this time slot is much drier than that in the active wet monsoon period (Fig. 4). Recall that the monsoon ridge influences Darwin, north Australia. As analyzed by Xie et al. (2010), the midlevel subsidence and horizontal dry advection are largely responsible for the dry mid-troposphere observed during the suppressed period and limit the growth of clouds to low levels. For the vertical cross-section of the mean wind speed (Fig. 8), the westerly winds increase to the east of Darwin between 850 and $700 \mathrm{hPa}$ with the sounding data assimilation (Fig. 8b). During the individual day of the suppressed monsoon period, significant mid-level dry air intrusion starts from 27 January. One day later, the relative humidity at the $650-\mathrm{hPa}$ level decrease to less than $30 \%$ (Fig. 9) and the other dry center is at the $750-\mathrm{hPa}$ level. With the assimilated sounding data, the strengthening of the southwesterly-to-westerly winds $\left(>20 \mathrm{~m} \mathrm{~s}^{-1}\right)$ is apparently located between 850 and $700 \mathrm{hPa}$ (Fig. 9b). This implies that
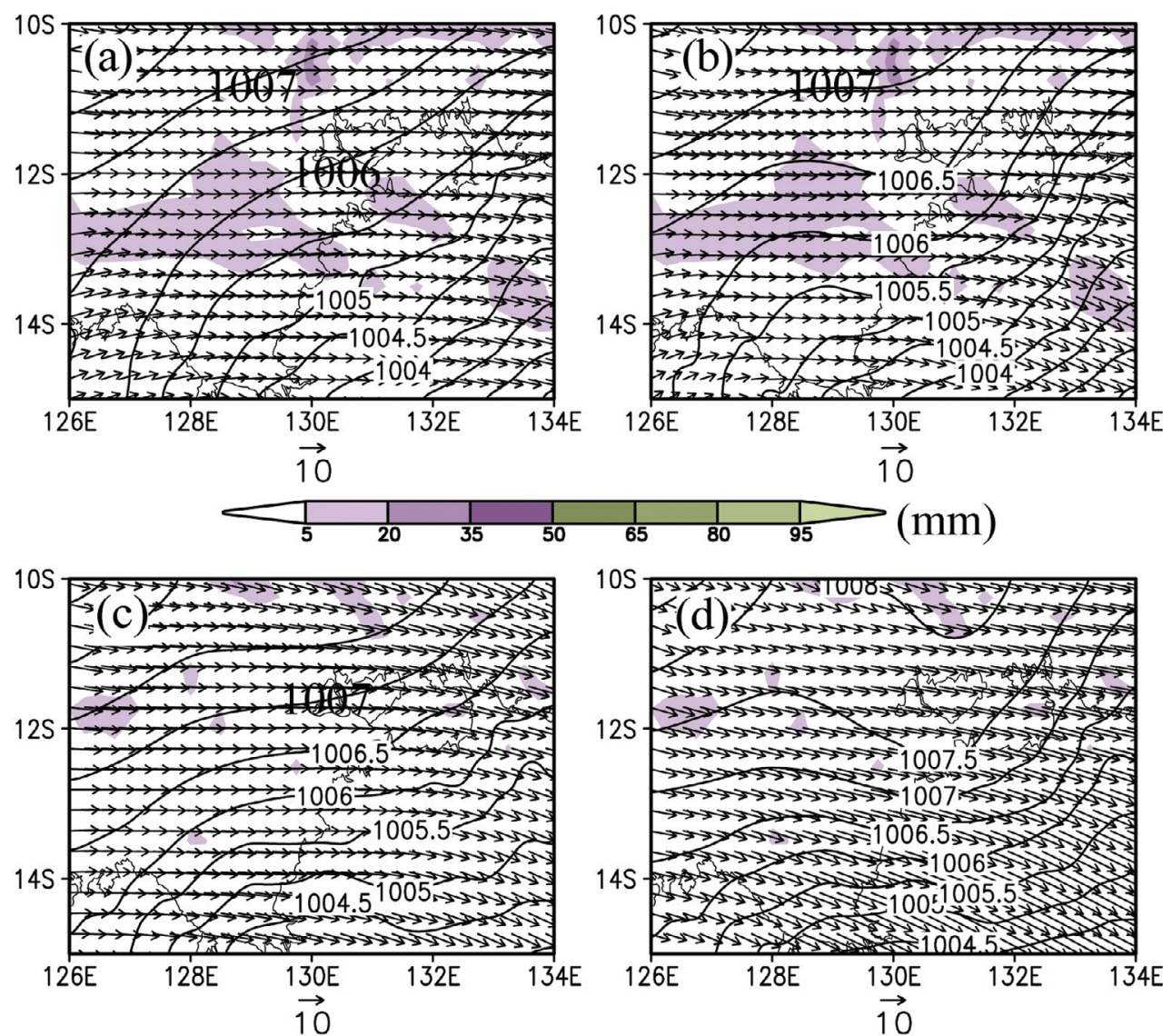

Fig. 6. (a) TRMM daily rainfall, NCEP/FNL sea-level pressure and 950-hPa wind vector (0000 UTC) on 29 January 2006, (b) TRMM daily rainfall, sea-level pressure and 950-hPa wind vector (0000 UTC) with the assimilated sounding data on 29 January, (c) same as (a) but for 30 January, and (d) same as (b) but for 30 January. The rainfall (shading) with a $15 \mathrm{~mm}$ interval starts from $5 \mathrm{~mm}$. The contour of sea-level pressure has the interval of $0.5 \mathrm{hPa}$. 
the strong southwesterly-to-westerly flow transports dry air from subtropical regions to northern Australia and the nearby tropical ocean. At 0000 UTC on 31 January (Fig. 10), the driest center $(\mathrm{RH}<20 \%)$ shown with sounding data as- similation locates between 600 and $550 \mathrm{hPa}$ near Darwin (Fig. 10b). The westerly winds are also enhanced to the east of Darwin between 850 and $700 \mathrm{hPa}$ through the incorporation of additional sounding data.
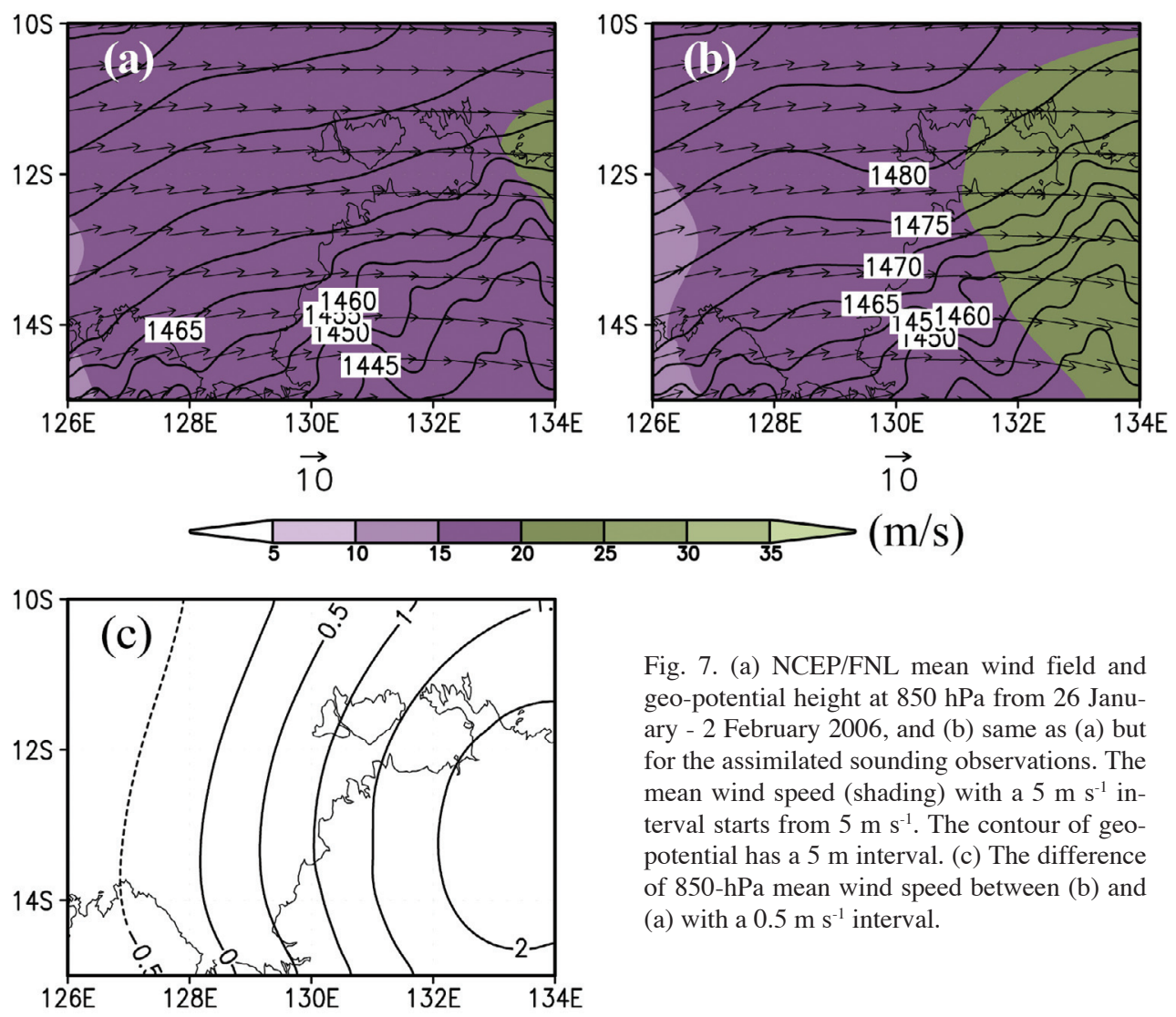

Fig. 7. (a) NCEP/FNL mean wind field and geo-potential height at $850 \mathrm{hPa}$ from 26 January - 2 February 2006, and (b) same as (a) but for the assimilated sounding observations. The mean wind speed (shading) with a $5 \mathrm{~m} \mathrm{~s}^{-1}$ interval starts from $5 \mathrm{~m} \mathrm{~s}^{-1}$. The contour of geopotential has a $5 \mathrm{~m}$ interval. (c) The difference of $850-\mathrm{hPa}$ mean wind speed between (b) and (a) with a $0.5 \mathrm{~m} \mathrm{~s}^{-1}$ interval.
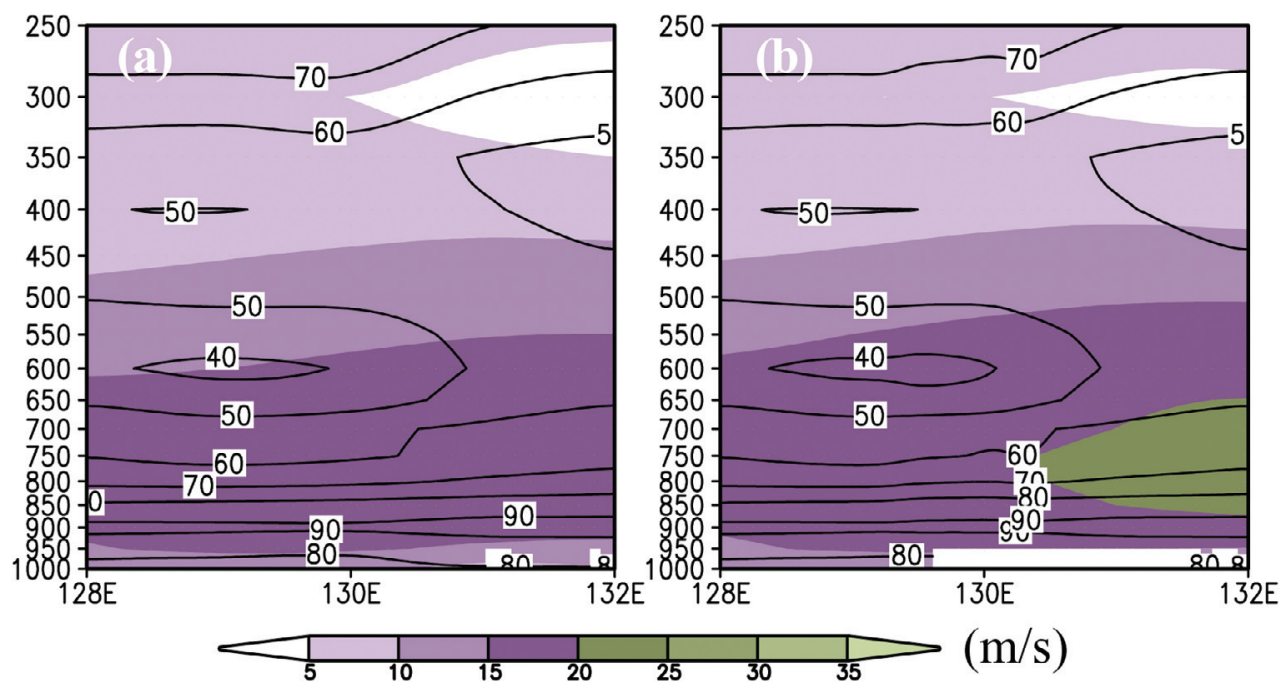

Fig. 8. (a) Vertical cross-section of NCEP/FNL mean wind speed and relative humidity along the Darwin (lat $=-12.24$ ) from 26 January -2 February 2006, and (b) same as (a) but for assimilated sounding observations. The mean wind speed (shading) with a $5 \mathrm{~m} \mathrm{~s}^{-1}$ interval starts from $5 \mathrm{~m} \mathrm{~s}^{-1}$. The contour of the relative humidity has a $10 \%$ interval. 


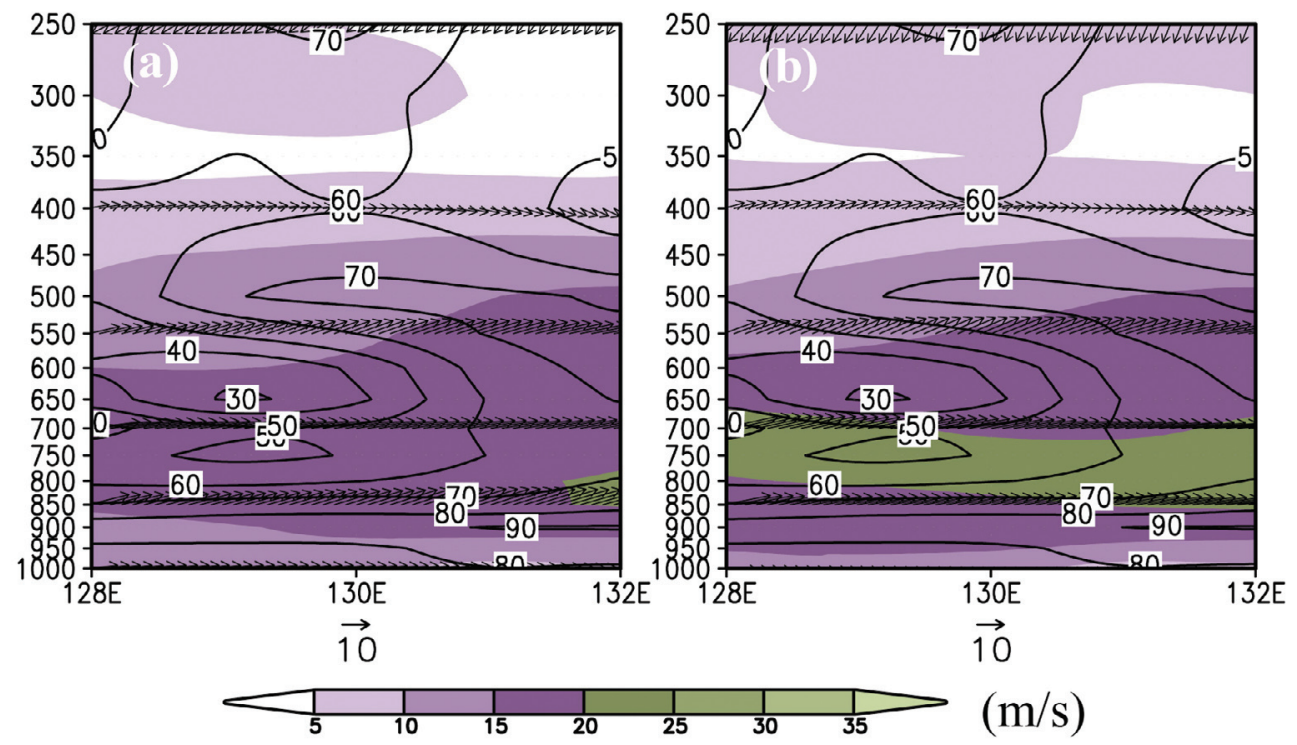

Fig. 9. (a) Vertical cross-section of NCEP/FNL wind field and relative humidity along the Darwin (lat $=-12.24$ ) at 0000 UTC on 28 January 2006 , and (b) same as (a) but for assimilated sounding observations. The mean wind speed (shading) with a $5 \mathrm{~m} \mathrm{~s}^{-1}$ interval starts from $5 \mathrm{~m} \mathrm{~s}^{-1}$. The contour of the relative humidity has a $10 \%$ interval.

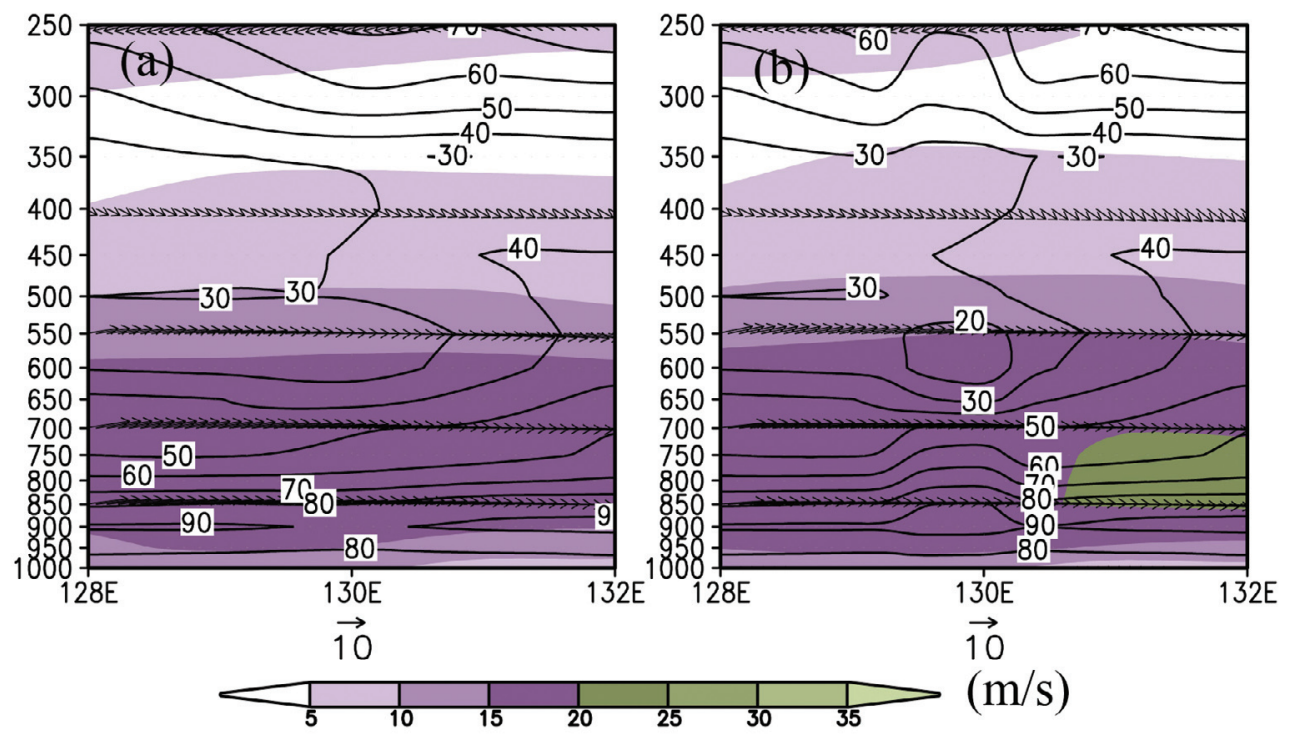

Fig. 10. (a) Vertical cross-section of NCEP/FNL wind field and relative humidity along the Darwin (lat $=-12.24$ ) at 0000 UTC on 31 January 2006 , and (b) same as (a) but for assimilated sounding observations. The mean wind speed (shading) with a $5 \mathrm{~m} \mathrm{~s}^{-1}$ interval starts from $5 \mathrm{~m} \mathrm{~s}^{-1}$. The contour of the relative humidity has a $10 \%$ interval.

Following the suppressed monsoon period, the clear days (3 - 6 February 2006) is characterized by a quasistationary monsoon ridge and weak westerlies over north Australia during 3 - 4 February (Fig. 11) with the help of additional sounding data (Figs. $11 \mathrm{~b}$ and $\mathrm{d}$ ) compared with the NCEP/FNL global analysis (Figs. 11a and c). The sealevel pressure gradient (Fig. 11) is relatively weak and the TRMM rainfall is also much less than the active wet monsoon period. From the vertical cross-section of mean wind speed and the relative humidity (Fig. 12), the atmospheric conditions reveal that the moisture content is really dry with a relative humidity less than $50 \%$ above the $800-\mathrm{hPa}$ level. The subsidence related to the monsoon ridge results mainly in the drying of the atmosphere. At 0000 UTC on 4 February, the mid-troposphere subsidence is the most significant with relative humidity less than $10 \%$ in Darwin (Fig. 13). Here, the dynamical and moisture-content adjustment with the assimilated additional sounding data (Fig. 13b) is also 

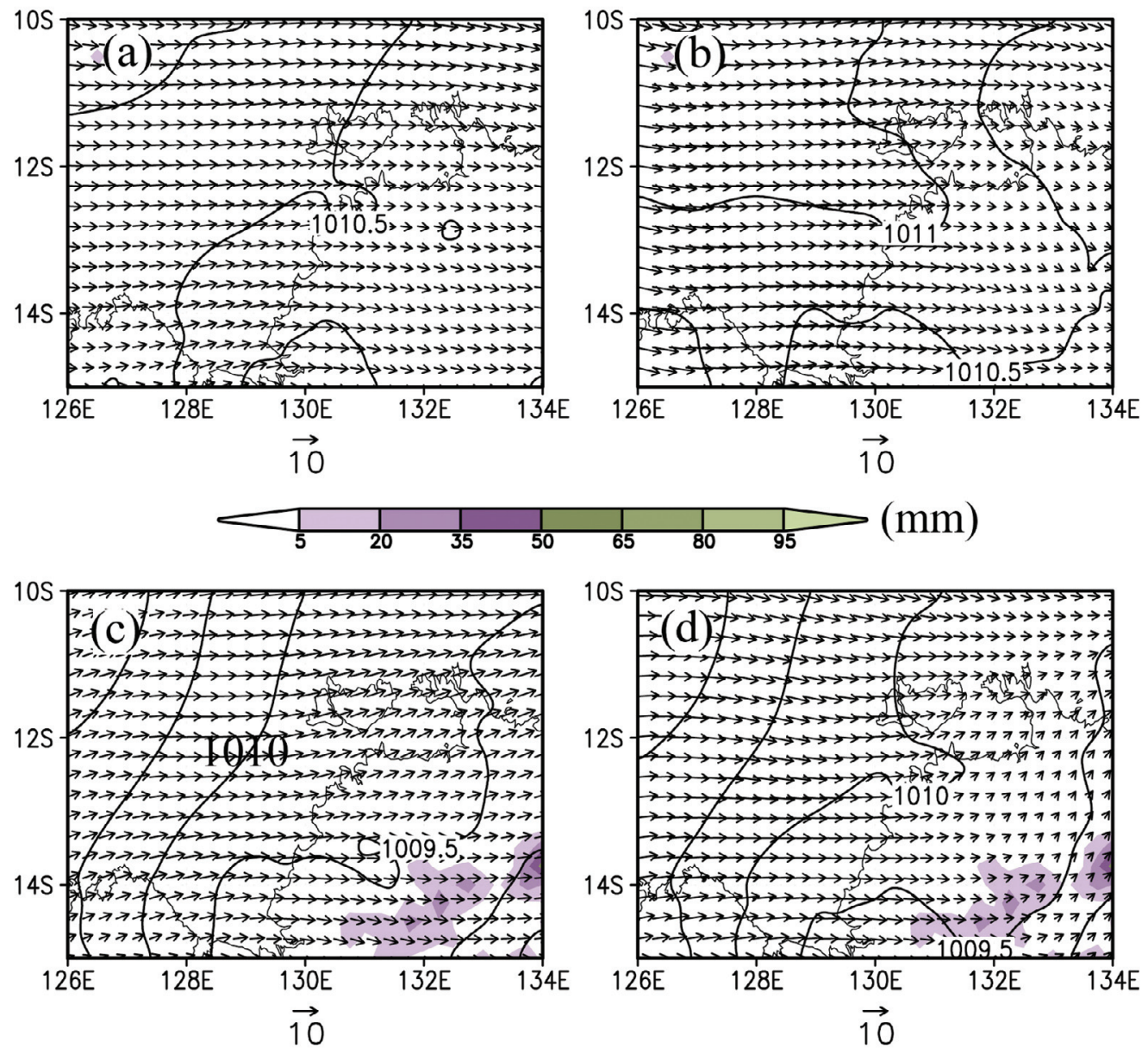

Fig. 11. (a) TRMM daily rainfall, NCEP/FNL sea-level pressure and 950-hPa wind vector (0000 UTC) on 3 February 2006, (b) TRMM daily rainfall, NCEP/FNL sea-level pressure and 950-hPa wind vector (0000 UTC) with the assimilated sounding data on 3 February, (c) same as (a) but for 4 February, and (d) same as (b) but for 4 February. The rainfall (shading) with a $15 \mathrm{~mm}$ interval starts from $5 \mathrm{~mm}$. The contour of sea-level pressure has the interval of $0.5 \mathrm{hPa}$
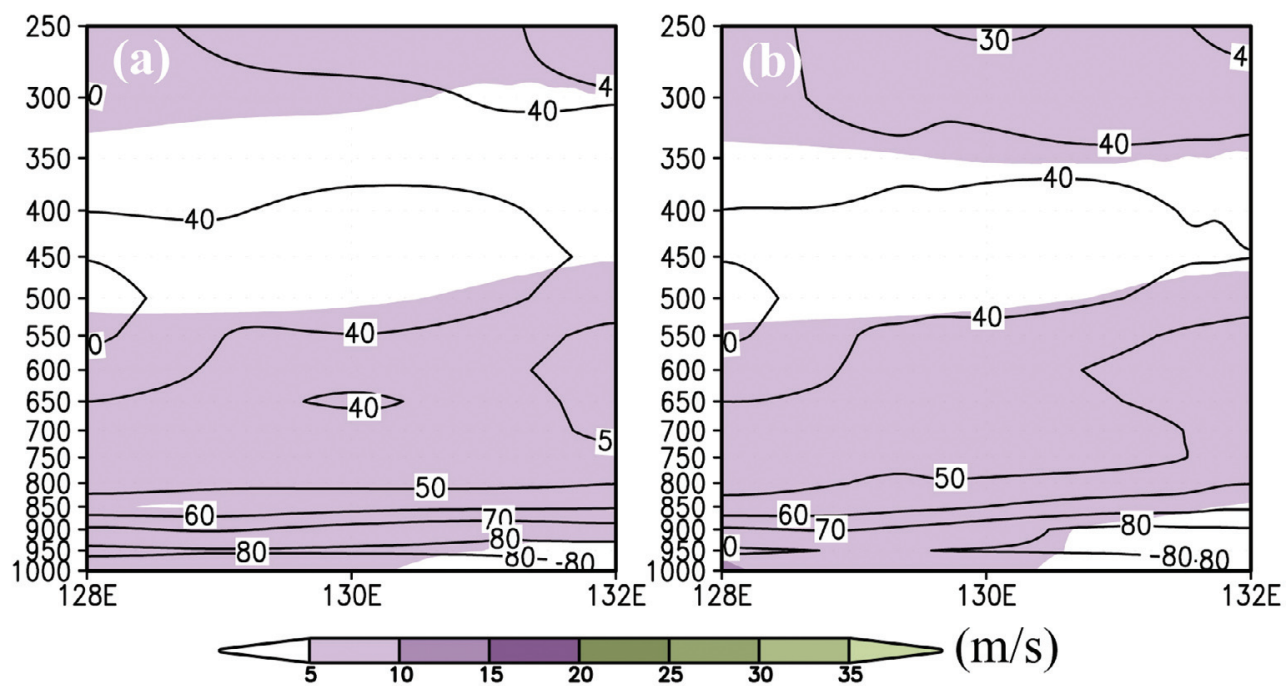

Fig. 12. (a) Vertical cross-section of NCEP/FNL mean wind speed and relative humidity along the Darwin (lat $=-12.24)$ during $3-6$ February 2006, and (b) same as (a) but for assimilated sounding observations. The mean wind speed (shading) with a $5 \mathrm{~m} \mathrm{~s}^{-1}$ interval starts from $5 \mathrm{~m} \mathrm{~s}^{-1}$. The contour of the relative humidity has a $10 \%$ interval. 


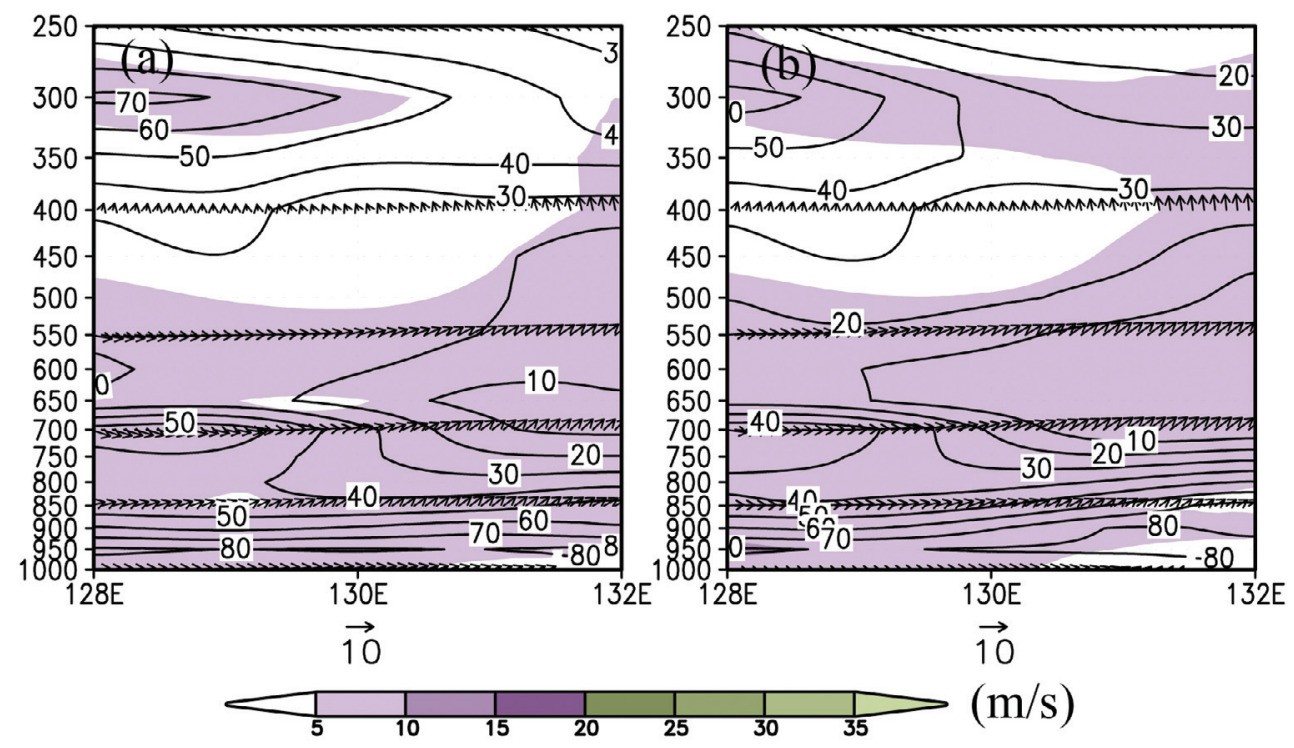

Fig. 13. (a) Vertical cross-section of NCEP/FNL wind field and relative humidity along the Darwin (lat $=-12.24$ ) at 0000 UTC on 4 February 2006 , and (b) same as (a) but for assimilated sounding observations. The mean wind speed (shading) with a $5 \mathrm{~m} \mathrm{~s}^{-1}$ interval starts from $5 \mathrm{~m} \mathrm{~s}^{-1}$. The contour of the relative humidity has a $10 \%$ interval.

revealed in the wind field and the relative humidity compared with the NCEP/FNL analysis (Fig. 13a).

After the suppressed monsoon and clear days, the monsoon low-pressure system appears inland again with a relatively weak sea-level pressure gradient (Fig. 14) during the monsoon break ( 7 - 10 February 2006). After assimilating additional sounding observations, the monsoon low is enhanced (Figs. 14b and d) over land compared with the NCEP/FNL analysis (Figs. 14a and c) during 9 - 10 February. The westerly wind in low levels weakens and changes to the southwesterlies and southerlies (Fig. 14). The weak TRMM rainfall distributes over land in the north Australia (Fig. 14). For the vertical atmospheric profiles, the westerly winds change to the southeasterly-to-easterlies between 850 and $700 \mathrm{hPa}$ (Fig. 15). Recall that the typical westerly winds between 850 and $700 \mathrm{hPa}$ are also absent in the active monsoon regime under the influence of the monsoon low pressure system. The wind speed decreases and becomes weaker than that in the wet and dry monsoon regimes. The moisture content reduces slightly with the assimilation of additional sounding data (Fig. 15b).

\section{RAINFALL PREDICTION}

Through the assimilation of the additional sounding data over the north Australia and the surrounding ocean, the impact on daily rainfall predictions during the IOP of TWP-ICE, especially in the active monsoon period, are statistically investigated. Recall that the heavy rainfall events (> $100 \mathrm{~mm} \mathrm{day}^{-1}$ ) occur primarily during the active monsoon period (Fig. 2). In contrast, the other temporal regimes have no significant rainfall as revealed by the TRMM rainfall distribution (Figs. 6, 11, and 14).

For the active monsoon period, the convection is very active under the influence of a monsoon low pressure system. Heavy rainfall appears during 23 - 24 January (Fig. 2) over the nearby tropical ocean of north Australia and the maritime continent centered on the Tiwi Islands. Recall that the dilute CAPE in this period is much stronger than the other temporal regimes (Zhang 2009). The predicted daily rainfall rate (Fig. 16) with assimilated sounding data during 23-24 January reproduces heavy rainfall in the nearby ocean to the west of Tiwi Island (Fig. 16b). Also, the rainfall distribution $\left(>60 \mathrm{~mm} \mathrm{day}^{-1}\right)$ is relatively consistent with the satellite-retrieved TRMM rainfall (Fig. 16c), compared with the rainfall prediction using NCEP/FNL as initial conditions (Fig. 16a). For the area-averaged $\left(128-130^{\circ} \mathrm{E} ; 13.5\right.$ $-10.5^{\circ} \mathrm{S}$ ) daily rainfall during 23 - 24 January 2006 , the prediction with the sounding data assimilated reproduces the rainfall of $68.2 \mathrm{~mm} \mathrm{day}^{-1}$ over the ocean is closed to the TRMM rainfall $\left(67.1 \mathrm{~mm} \mathrm{day}^{-1}\right)$, and is relatively larger than the rainfall $\left(64.1 \mathrm{~mm} \mathrm{day}^{-1}\right)$ predicted by the NCEP/ FNL run.

In addition, the statistical evaluation, using the MAE and bias as shown in section 2.3, for the daily rainfall predictions with and without additional sounding data assimilation during 22 - 25 January 2006 is presented in Figs. 17 and 18 , respectively. With additional assimilated soundings, the daily rainfall prediction reveals smaller errors in MAE (Fig. 17) compared with those predicted by the NCEP-FNL. The bias also shows a better performance with additional sounding assimilation (Fig. 18) than the NCEP-FNL run, 

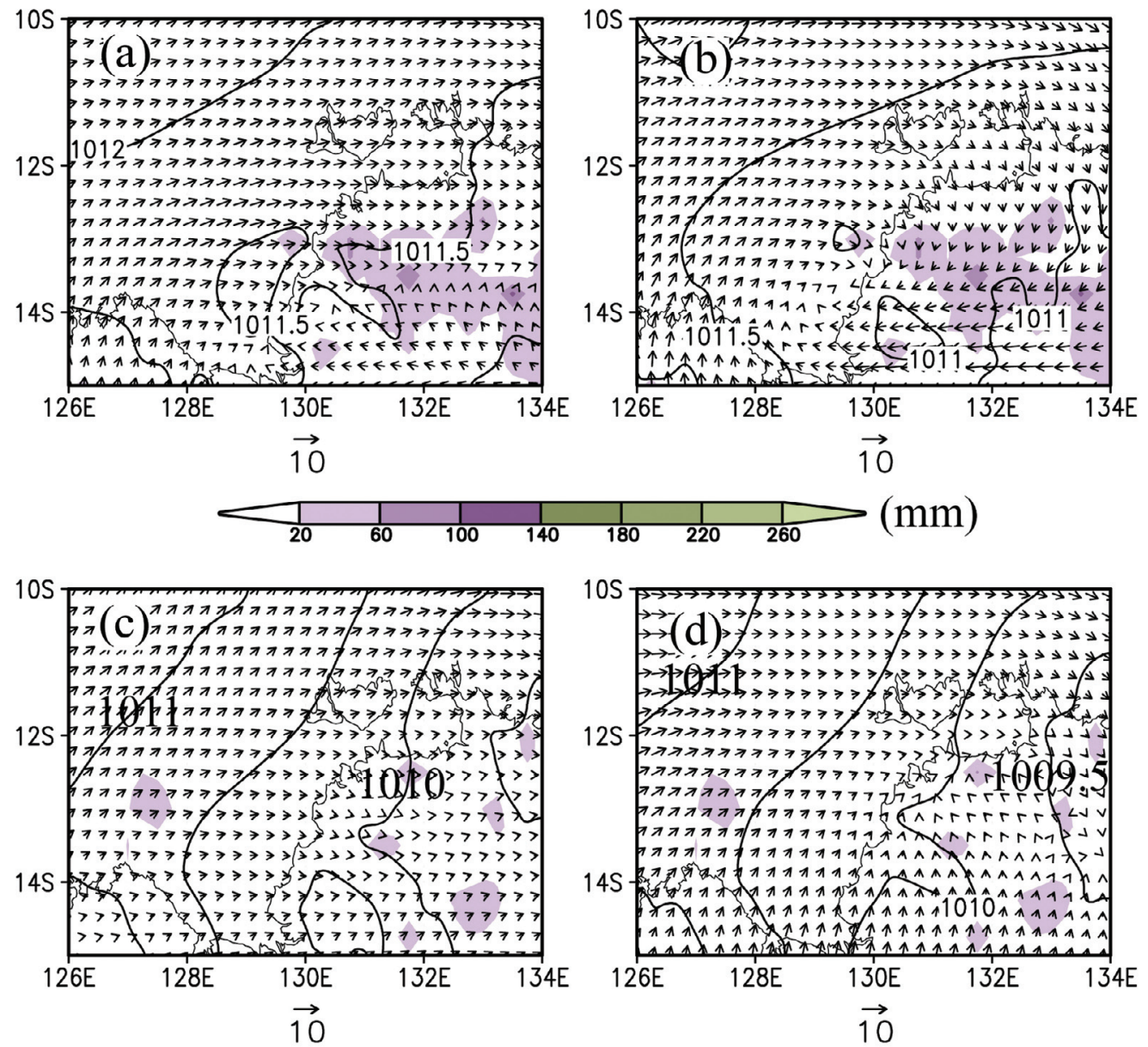

Fig. 14. (a) TRMM daily rainfall and NCEP/FNL sea-level pressure (0000 UTC) on 9 February 2006, (b) TRMM daily rainfall and sea-level pressure (0000 UTC) with the assimilated sounding data on 9 February, (c) same as (a) but for 10 February, and (d) same as (b) but for 10 February. The rainfall (shading) with a $40 \mathrm{~mm}$ interval starts from $20 \mathrm{~mm}$. The contour of sea-level pressure has the interval of $0.5 \mathrm{hPa}$.
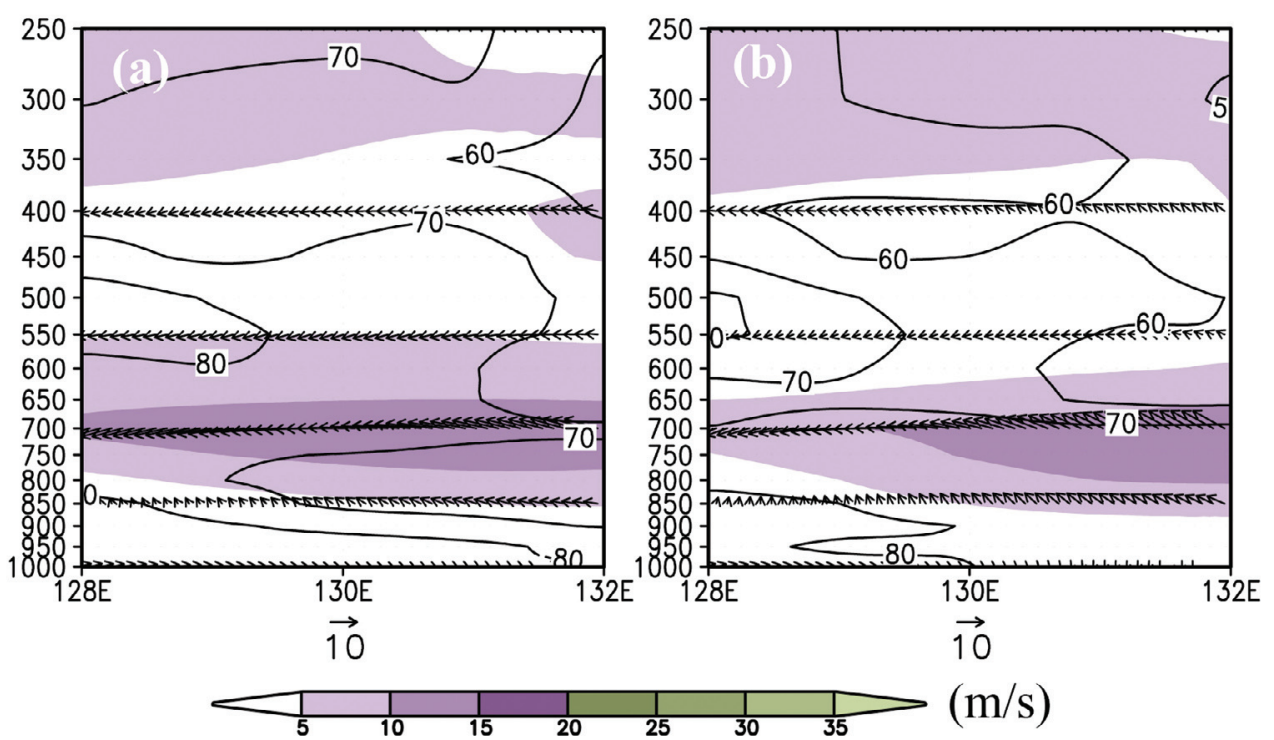

Fig. 15. (a) Vertical cross-section of NCEP/FNL wind field and relative humidity along the Darwin (lat $=-12.24$ ) at 0000 UTC on 10 February 2006 , and (b) same as (a) but for assimilated sounding observations. The mean wind speed (shading) with a $5 \mathrm{~m} \mathrm{~s}^{-1}$ interval starts from $5 \mathrm{~m} \mathrm{~s}^{-1}$. The contour of the relative humidity has a $10 \%$ interval. 

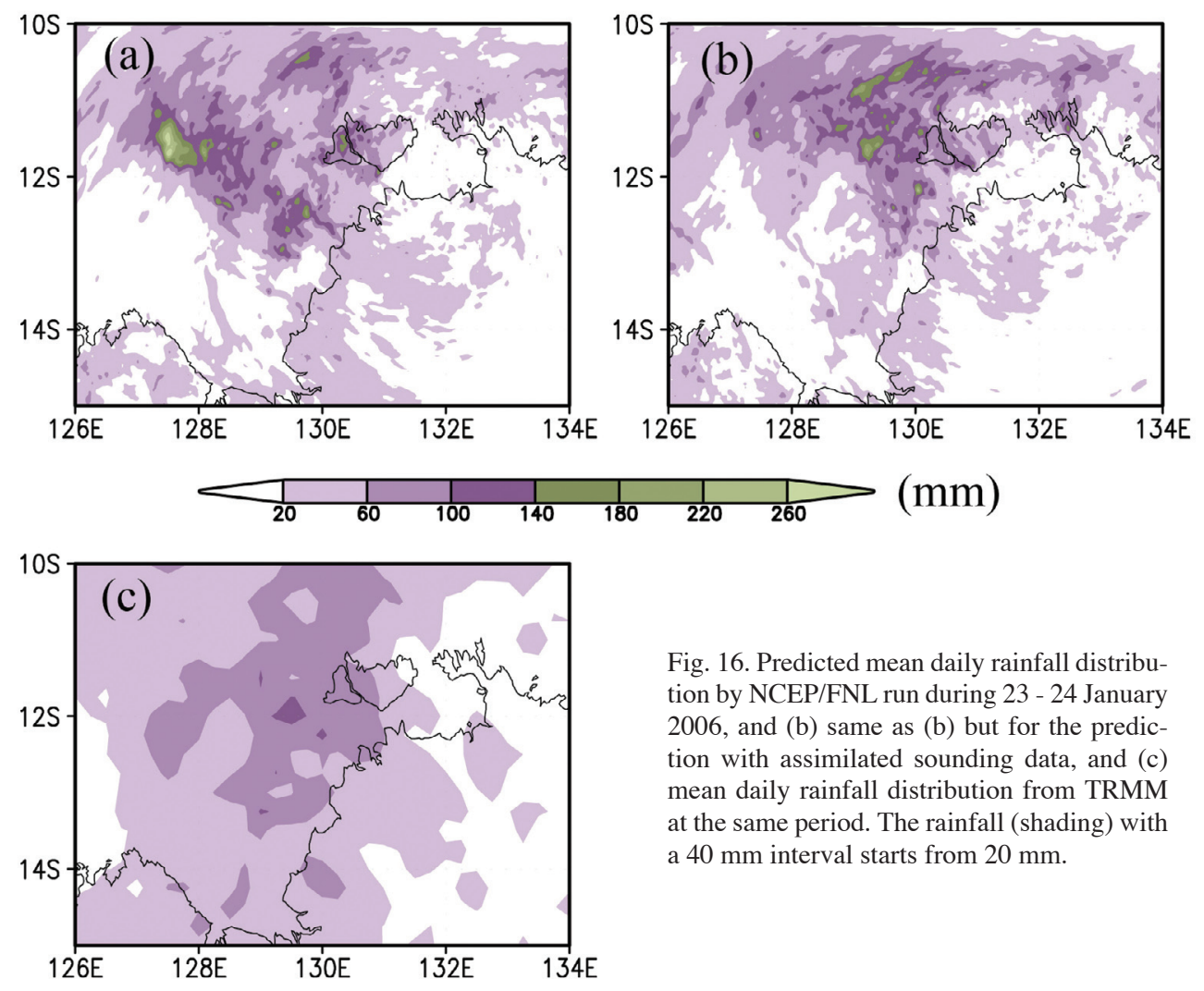

Fig. 16. Predicted mean daily rainfall distribution by NCEP/FNL run during 23 - 24 January 2006, and (b) same as (b) but for the prediction with assimilated sounding data, and (c) mean daily rainfall distribution from TRMM at the same period. The rainfall (shading) with a $40 \mathrm{~mm}$ interval starts from $20 \mathrm{~mm}$.

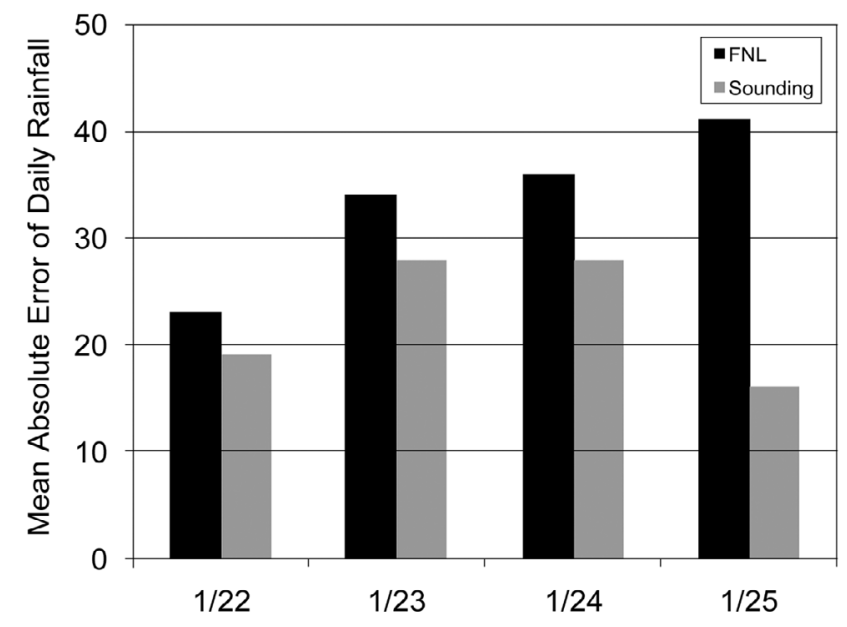

Fig. 17. The mean absolute error (MAE) in predicted daily rainfall associated with NCEP-FNL runs (black box), and the simulations with additional soundings assimilated (grey box) from 22 - 25 January 2006.

although the predicted rainfall in both is under-predicted as compared with the TRMM rainfall. Therefore, to assimilate more sounding observations can improve the daily rainfall prediction over the nearby ocean west of Tiwi Island and the northern Australia in the active monsoon period.

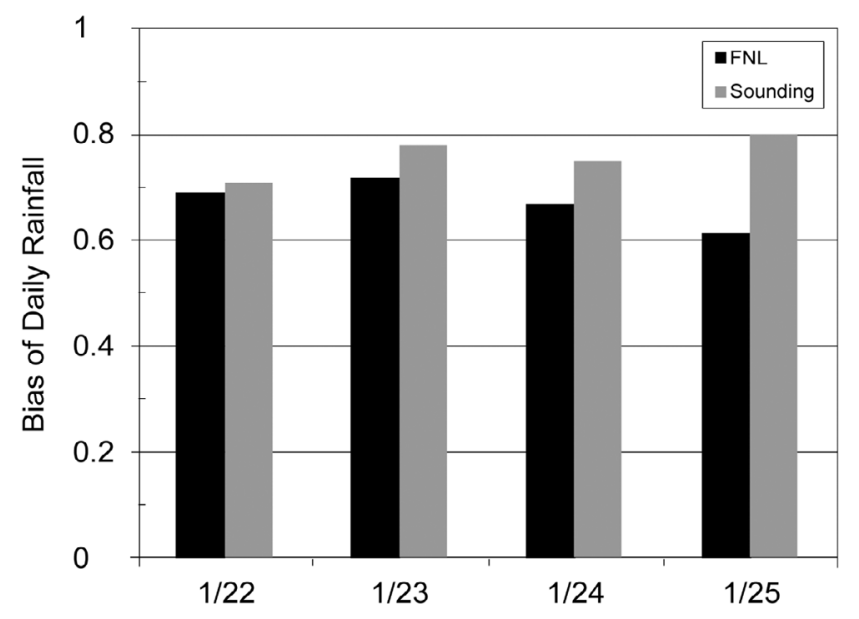

Fig. 18. Bias in predicted daily rainfall associated with NCEP-FNL runs (black box), and the simulations with additional soundings assimilated (grey box) from 22 - 25 January 2006.

\section{CONCLUSION}

With the availability of additional sounding observations during IOP of 2006 TWP-ICE over north Australia and surrounding ocean of the Tiwi Island, the characteris- 
tics of weather systems and atmospheric conditions during four temporal regimes (active wet monsoon, suppressed monsoon, clear days, and monsoon break) can be further analyzed using the WRF 3D-Var system.

In the active wet monsoon period (21 - 25 January 2006), a monsoon low-pressure system dominates over coastal regions of northern Australia. The environmental moisture content is much wet compared with the following periods. Thus, heavy rainfall is revealed by the TRMM daily rainfall over the nearby ocean of the Tiwi Island and northern Australia, where the southerly-to-southwesterly winds predominate in low levels. This is different from the typical westerly winds during active north Australia summer monsoon regime. In addition, the daily rainfall predictions with additional sounding assimilation have significant improvement over the nearby ocean of the Tiwi Island and the northern Australia during 22 - 25 January 2006.

For the suppressed monsoon period (26 January - 2 February 2006), a monsoon ridge approaches Tiwi Island and northern Australia. A monsoon low-pressure system develops and deepens inland. The sea-level pressure gradient increases significantly where strong westerly winds in low levels are revealed and strengthened with the assimilation of additional soundings. Meanwhile, significant dry air intrusion occurs in the mid-troposphere with a driest center around the $600-\mathrm{hPa}$ level. The dry mid-troposphere may relate to the air advection from the subtropical regions and the subsidence as also revealed by Xie et al. (2010). Thus, the rainfall production is reduced sharply over the nearby ocean north of Australia and the Tiwi Island compared with the active monsoon period. However, the driest conditions occur during the clear days with the relative humidity less than $10 \%$ in middle levels, primarily due to the subsidence under the influence of a monsoon ridge. For the monsoon break period (7 - 10 February 2006), the weather is dominated by a monsoon low. The sea-level pressure gradient and the low-level winds over the ocean become weaker as compared with the active wet monsoon period. Scattered rainfall is distributed over coastal regions of northern Australia.

Acknowledgements This work is supported by DOE (DESC0002134) and the International Pacific Research Center (IPRC) that is sponsored by the Japan Agency for MarineEarth Science and Technology (JAMSTEC), NASA and NOAA. Thanks to anonymous reviewers for valuable suggestions and the Tropical Warm Pool-International Cloud Experiment (TWP-ICE) for additional sounding observations. Also, thanks to the TRMM Online Visualization and Analysis System (TOVAS) provided the satellite-retrieved rainfall. Data used in this study were acquired using the GES-DISC Interactive Online Visualization and analysis Infrastructure (Giovanni) as part of the NASA's Goddard Earth Sciences (GES) Data and Information Services Center
(DISC), and to NCAR MMM for providing the WRF 3DVar system.

\section{REFERENCES}

Barker, D. M., W. Huang, Y. R. Kuo, A. J. Bourgeois, and Q. Xiao, 2004: A three-dimensional variational data assimilation system for MM5: Implementation and initial results. Mon. Weather Rev., 132, 897-914, doi: 10.1175/1520-0493(2004)132<0897:ATVDAS>2.0. CO;2. [Link]

Chen, F. and J. Dudhia, 2001: Coupling an advanced land surface-hydrology model with the Penn State-NCAR MM5 modeling system. Part I: Model implementation and sensitivity. Mon. Weather Rev., 129, 569-585, doi: 10.1175/1520-0493(2001)129<0569:CAALSH>2.0. CO;2. [Link]

Drosdowsky, W., 1996: Variability of the Australian summer monsoon at Darwin: 1957-1992. J. Climate, 9, 8596, doi: 10.1175/1520-0442(1996)009<0085:VOTAS $\mathrm{M}>2.0 . \mathrm{CO} ; 2$. [Link]

Dudhia, J., 1989: Numerical study of convection observed during the winter monsoon experiment using a mesoscale two-dimensional model. J. Atmos. Sci., 46, 30773107, doi: 10.1175/1520-0469(1989)046<3077:NSOC OD>2.0.CO;2. [Link]

Ferrier, B. S., Y. Jin, Y. Lin, T. Black, E. Rogers, and G. DiMego, 2002: Implementation of a new grid-scale cloud and precipitation scheme in the NCEP Eta model. Preprints, $15^{\text {th }}$ Conf. on Numerical Weather Prediction, San Antonio, TX, American Meteorological Society, 280-283.

Janjić, Z. I., 1994: The step-mountain eta coordinate model: Further developments of the convection, viscous sublayer, and turbulence closure schemes. Mon. Weather Rev., 122, 927-945, doi: 10.1175/1520-0493(1994)122 $<0927$ :TSMECM>2.0.CO;2. [Link]

Janjić, Z. I., 2000: Comments on "Development and evaluation of a convection scheme for use in climate models." J. Atmos. Sci., 57, 3686-3686, doi: 10.1175/1520-0469 (2000)057<3686:CODAEO>2.0.CO;2. [Link]

May, P. T., J. H. Mather, G. Vaughan, K. N. Bower, C. Jakob, G. M. McFarquar, and G. G. Mace, 2008: The tropical warm pool international cloud experiment. Bull. Amer. Meteorol. Soc., 89, 629-645, doi: 10.1175/ BAMS-89-5-629. [Link]

Mlawer, E. J., S. J. Taubman, P. D. Brown, M. J. Iacono, and S. A. Clough, 1997: Radiative transfer for inhomogeneous atmosphere: RRTM, a validated correlated- $\mathrm{k}$ model for the longwave. J. Geophys. Res., 102, 16663 16682, doi: 10.1029/97JD00237. [Link]

Skamarock, W. C., J. B. Klemp, J. Dudhia, D. O. Gill, D. M. Barker, M. Duda, X. Y. Huang, W. Wang, and J. 
G. Powers, 2008: A Description of the Advanced Research WRF Version 3, NCAR Technical Note, NCAR/ TN-475+STR, 113 pp.

Wapler, K., T. P. Lane, P. T. May, C. Jakob, M. J. Manton, and S. T. Siems, 2010: Cloud-system-resolving model simulations of tropical cloud systems observed during the tropical warm pool-international cloud experiment. Mon. Weather Rev., 138, 55-73, doi: 10.1175/20 09MWR2993.1. [Link]

Wilks, D. S., 1995: Statistical Methods in the Atmospheric Sciences. Academic Press, 467 pp.

Xiao, Q. and J. Sun, 2007: Multiple-radar data assimilation and short-range quantitative precipitation forecasting of a squall line observed during IHOP_2002. Mon. Weather Rev., 135, 3381-3404, doi: 10.1175/MWR34 71.1. [Link]

Xiao, Q., X. Zhang, C. Davis, J. Tuttle, G. Holland, and P. J. Fitzpatrick, 2009: Experiments of hurricane initializa- tion with airborne Doppler radar data for the advanced research hurricane WRF (AHW) model. Mon. Weather Rev., 137, 2758-2777, doi: 10.1175/2009MWR2828.1. [Link]

Xie, S., T. Hune, C. Jakob, S. A. Klein, R. B. McCoy, and M. Zhang, 2010: Observed large-scale structures and diabatic heating and drying profiles during TWP-ICE. J. Climate, 23, 57-79, doi: 10.1175/2009JCLI3071.1. [Link]

Yeh, H. C., 2010: Application of satellite-derived ocean surface winds to the detection of weather systems and the prediction of near-ocean surface winds around Hawaii. Terr. Atmos. Ocean. Sci., 21, 955-969, doi: 10.3319/ TAO.2010.03.29.01(A). [Link]

Zhang, G. J., 2009: Effects of entrainment on convective available potential energy and closure assumptions in convection parameterization. J. Geophys. Res., 114, D07109, doi: 10.1029/2008JD010976. [Link] 